\title{
EVALUATION OF INDIVIDUAL AWARENESS OF DIABETES, RELATED RISK FACTORS AND COMPLICATIONS IN URBAN AND RURAL PEOPLE OF NOAKHALI REGION, BANGLADESH: A POPULATION- BASED STUDY
}

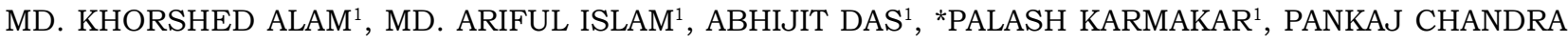 \\ DEBNATH $^{1}$, MONIKA RANI SAHA ${ }^{2}$
}

\begin{abstract}
This cross-sectional study was conducted to evaluate the individual awareness, related risk factors and complications of diabetes with socio-demographic profiles of the study individuals in Noakhali region, Bangladesh during June to December, 2013. A total 250 participants were selected randomly and data were collected using structured questionnaire. Among the respondents $47.20 \%$ were found male and $52.80 \%$ were female and majorities (52.00\%) of the respondents were urban people. Respondents completed secondary study level or below were the dominant group. 9.20\%, $27.20 \%, 12.80 \%$ and $34.40 \%$ respondents were agriculturist, businessman and housewives respectively. Women showed better knowledge about overall diabetes $(20.00 \%)$ and blood glucose level (9.60\%), in case of causes, symptoms and management men $(12.80 \%, 23.20 \%$ and $18.40 \%$ respectively) were found dominant than women (10.00\%, $16.00 \%$ and $12.00 \%$ respectively). It was found that $13.20 \%$ respondents were suffering from impaired glucose tolerance and $79.20 \%$ had diabetes mellitus where female were more vulnerable than male. Family history was found the significant risk factor $\left(p=0.016 ; C^{2}=5.849\right)$ for diabetes (total $62 \%$, male $40.65 \%$ and female 59.35\%), Other risk factors like age (67.20\%), obesity (46.40\%), hypercholesterolemia (82.00\%), excess triglyceride (78.00\%) and hypertension (29.60\%) remained insignificant respectively and in every cases female were found more vulnerable than men. Study revealed that knowledge regarding diabetes was not up to the mark to the respondents though it is now one of the most pandemic diseases in the world.
\end{abstract}

Keyword: Diabetes, Risk factors, Awareness, Complications, Noakhali region.

Received: 4 July 2015

Accepted: 3 November 2015

\section{Introduction}

Diabetes or diabetes mellitus (DM) is a group of metabolic diseases which is caused by hyperglycemia resulting from deficiency in insulin action, insulin secretion or both. The chronic hyperglycemic diabetes is closely related with long-term failure, damage, and dysfunction of various organs especially the eyes, nerves, kidneys, heart, and blood vessels. ${ }^{1}$ Individuals with undiagnosed type 2 diabetes are also at significantly higher risk for peripheral vascular disease, coronary heart disease, stroke and other related complications than the non-diabetic population. ${ }^{2}$ They also have a greater possibility of having obesity, dyslipidemia and hypertension. ${ }^{3}$
In recent days; Diabetes mellitus is a global epidemic and progressively a major non-communicable disease, threatening both developed and undeveloped society. ${ }^{4,5}$ It is estimated in the year 2000 that more than 170 million people worldwide suffer from diabetes. This figure is expected to more than double by 2030 if current trends continue allowing more. ${ }^{6}$ Due to the modern and sedentary lifestyle, unsatisfactory diet, increasing urbanization, comfort living and the increased incidence of obesity in the population it is predicted that there will be over 300 million people who will sustain diabetes mellitus by 2025. ${ }^{7}$ Approximately $80 \%$ of people with diabetes are living in low and middle-income countries to date. ${ }^{8}$

1. Department of Pharmacy, Noakhali Science and Technology University, Sonapur, Noakhali-3814, Bangladesh,

2. Department of Pharmacy, Rajshahi University, Rajshahi-6205, Bangladesh

Address of Correspondence: Dr. Palash Karmakar, Assistant Professor, Department of Pharmacy, Noakhali Science and Technology University, Sonapur, Noakhali-3814, Bangladesh, E-mail: pknstu@gmail.com Tel: +88-0321-71483 (Office), + 88-01717036968(Mobile) 
Current epidemiological reports emerged the increased prevalence of diabetes in Turkey (7.2\%), Pakistan (11.1\%), Hawaii (20.4\%). ${ }^{9,10}$ In European people, age ascertained prevalence differed from 3$10 \%$. Some Arab, Chinese, migrant Asian Indian, and Hispanic American populations were at higher risk with prevalence ranging 14-20\%. The highest prevalence's were found in the Pima/ Papago Indians $50 \%$ and the Nauruan $41 \% .{ }^{11}$ It will mostly increase in South Asia where India and China has been declared as the capital of diabetic world. ${ }^{12}$ China was home to the largest number of adults with diabetes about 90 million which is $9 \%$ of the total population, followed by India $(61.3$ million or $8 \%$ of the total population). ${ }^{8}$

Bangladesh has a population of 149.8 million in $2011 .{ }^{13}$ A recent meta-analysis showed that the prevalence of diabetes among adults had raised dramatically from $4 \%$ in 1995 to $2000,5 \%$ in 2001 to 2005 and $9 \%$ in 2006 to $2010 .{ }^{14}$ International Diabetes Federation (IDF) accounted and anticipated that, the prevalence will be $13 \%$ by $2030 .^{8}$ This explosion in diabetes prevalence will place Bangladesh among the top ten countries in terms of the number of people living with diabetes in 2025. ${ }^{15}$ The non-communicable diseases like hypertension, diabetes and asthma are now highly prevalent diseases worldwide. Among these, the prevalence of hypertension and diabetes are increasing rapidly. The risk factors related to these disorders were more prevalent in Bangladeshis than in the native population. ${ }^{16,17}$ In Bangladesh, these non-communicable diseases are emerging as a major health problems and the government has given them high research priority. ${ }^{18}$ It must be mentioned that a vast majority $(77.6 \%)$ of the national population lives in rural area (Bangladesh Bureau of Statistics 2000). [19] Some population-based studies conducted in Bangladesh in different time and have revealed the increasing trends of diabetes prevalence ranging from 1.5 to $3.8 \%$ in rural communities. ${ }^{20,21}$ Another study showed that in both urban and rural areas the highest prevalence of Non Insulin Dependent Diabetes Mellitus (NIDDM) was noticed among the rich and the poor socioeconomic classes exhibit the lowest prevalence. The rural rich have much higher prevalence of Impaired Glucose Tolerance (IGT) than their urban counterpart (16.5 vs. $4.4 \%) .^{22}$

However, there is a very few epidemiological study of the prevalence of diabetes mellitus and its risk factors has been carried out in the country. Moreover, no previous study has fully assessed the awareness of people to diabetes, risk factors and related complications. For optimum management of Diabetes and related complications requires individual awareness of the nature and consequence of the disease, its risk factors, dimensions of treatment and its complications. ${ }^{23,24}$ So that this study aimed to find out related risk factors of diabetes and awareness of people to diabetes and related complications in order to suggest possible interventions through laboratory evaluation of individual's glucose level and assessment of their awareness of diabetes, related risk factors and diabetes related complications through a structured questionnaire administered among the people from Noakhali district which is located on the southern-east part of the Bangladesh. ${ }^{25,26}$

\section{Materials \& Methods}

Study design and area

Study was conducted to evaluate individual awareness of diabetes and its risk factors and also to determine the awareness of respondents to diabetes related complications by collecting both qualitative and quantitative data randomly through a survey using well-structured questionnaire as a main tool. The study was done among the people of Noakhali district dividing in two groups as urban and rural area. Noakhali municipality, Kabirhat municipality, Choumuhani of Begumganj upazila and town area of Senbag upazila were considered as urban areas. On the other hand 95 Noakhali mouza of Noakhali sadar upazila, Sonaimuri upazila, Eklashpur union of Begumganj upazila, Burrir char union of Hatia upazila, Subarna Char upazila were considered as rural part of the study area during the survey. ${ }^{27}$

\section{Sample size}

To select the study participants, a simple random sampling technique was used. The sample size was determined by using a single population formula considering the following assumptions: Proportion of diabetic patients $20 \%$ taken from 2011 BDHS; ${ }^{19} 95 \%$ level of confidence $(Z=1.96) ; 5 \%$ marginal error. Thus with all participants in each cluster included, a final sample size of 245 was achieved. For the ease of data analysis a final sample size of 250 was taken. Only easily reachable respondents who were available at different Diabetic health complex, hospitals and physicians practice places were included in the study. Meanwhile people who were not easily reachable or who did not cooperate willingly were kept out of the study.

\section{Questionnaire preparation and data collection}

A questionnaire was prepared based on age, gender, body mass index, education, health status of the patients, fasting blood glucose level, presence or absence of other diseases, awareness about diabetes related complications, treatment system, etc. to collect information from each respondent. Respondents were interviewed face to face at the diabetic health complex or hospital. The data of the glucose level in the blood was collected from the guide book of respondents with their oral consent. 


\section{Statistical analysis}

After collection of data, these were summarized and scrutinized carefully and recorded. Finally relevant tables and graphs were prepared and statistical analysis was performed in accordance with the objective of the study using SPSS for Windows (version 16) (SPSS Inc., Chicago, IL, USA). Proportions and $95 \%$ confidence intervals $(95 \% \mathrm{CI})$ were calculated using descriptive statistics. The chi-square and $\mathrm{p}$ values were calculated by chi-square test and t-test, using analytic statistics. An alpha level of 0.05 or less was considered significant.

\section{Results}

Socio-demographic characteristics of the respondents

The socio-demographic characteristics of the respondents are shown in Table-I. Among the 250 participants about $47.20 \%$ were male and $52.80 \%$ were female. The age range of respondents was from 20 to above 70 years where a major portion, $67.20 \%$, of the respondents were above the age of 45 years and about $32.80 \%$ respondents were under 45 years of age. No of respondents from urban and rural area were 130 $(52.00 \%)$ and $120(48.00 \%)$ respectively.

Table-I

Demographic details of the survey population

\begin{tabular}{|c|c|}
\hline Parameters & Total (\%) \\
\hline \multicolumn{2}{|l|}{ Gender } \\
\hline Male & $118(47.20)$ \\
\hline Female & $132(52.80)$ \\
\hline \multicolumn{2}{|l|}{ Age } \\
\hline$<45$ & $82(32.80)$ \\
\hline$>45$ & $168(67.20)$ \\
\hline \multicolumn{2}{|l|}{ Educational Status } \\
\hline Nil & $24(9.60)$ \\
\hline Primary & $65(26.0)$ \\
\hline Under S.S.C. & $53(21.20)$ \\
\hline Vocational/S.S.C. & 43 (17.20) \\
\hline H.S.C. & $29(12.0)$ \\
\hline Bachelors & $13(6.0)$ \\
\hline Masters & $1(0.40)$ \\
\hline No Response & $19(7.60)$ \\
\hline \multicolumn{2}{|l|}{ Settlement Area } \\
\hline Urban & $130(52.0)$ \\
\hline Rural & $120(48.0)$ \\
\hline \multicolumn{2}{|l|}{ Occupation } \\
\hline Agriculture & $23(9.20)$ \\
\hline Housewife & $86(34.40)$ \\
\hline Employee & $68(27.20)$ \\
\hline Business & $32(12.80)$ \\
\hline Student & $05(2.0)$ \\
\hline No response & $20(8.0)$ \\
\hline Nothing & $16(6.40)$ \\
\hline
\end{tabular}

From the study results it is seen that just above $18.00 \%$ of these respondents had completed their study to H.S.C. level or above while the percentage of respondents who had only completed their education up to S.S.C. level or below S.S.C. were $17.20 \%$ and $47.20 \%$ respectively. Furthermore, $9.60 \%$ of them were illiterate and $7.60 \%$ respondents were irresponsive. Our survey results also focused that about $9.20 \%$ respondents had agriculture as their occupation while $27.20 \%$ were employees, $12.80 \%$ were businessman and $34.40 \%$ were housewives.

\section{Awareness of the respondents about diabetes}

During the study the respondent were asked several questions to judge their awareness about proper diabetes and the obtained results were recorded in Table-II. This study revealed that most of the study subjects had poor conception about diabetes, its causes and management. It is observed that about $28.80 \%, 18.40 \%, 20.00 \%$ and $25.20 \%$ male had poor conception about diabetes, its causes, symptoms and managements in comparison to that of $26.00 \%$, $22.00 \%, 27.20 \%$ and $32.80 \%$ to that of the female respectively. It is obvious that men had better conception about the causes, symptoms and management of diabetes $(12.80 \%, 23.20 \%$ and $18.40 \%$ respectively) than the women $(10.00 \%, 16.00 \%$ and $12.00 \%$ respectively). Furthermore, it was seen that women had better conception about diabetes $(20.00 \%)$ and blood glucose level $(9.60 \%)$ in respect of men's awareness of $13.20 \%$ and $8.00 \%$.

Table-II

Awareness level of the respondents about diabetes

\begin{tabular}{cccc}
\hline $\begin{array}{l}\text { Level of } \\
\text { conception }\end{array}$ & Yes & No & Poor \\
\hline $\begin{array}{c}\text { Conception about diabetes } \\
\text { Male }\end{array}$ & $33(13.20 \%)$ & $13(5.20 \%)$ & $72(28.80 \%)$ \\
Female & $50(20.00 \%)$ & $17(6.80 \%)$ & $65(26.00 \%)$ \\
Conception about cause of diabetes & \\
Male & $32(12.80 \%)$ & $40(16.00 \%)$ & $46(18.40 \%)$ \\
Female & $25(10.00 \%)$ & $52(20.80 \%)$ & $55(22.00 \%)$ \\
Conception about symptoms of diabetes & \\
Male & $58(23.20 \%)$ & $10(4.00 \%)$ & $50(20.00 \%)$ \\
Female & $40(16.0 \%)$ & $14(5.60 \%)$ & $68(27.20 \%)$ \\
Conception about management of diabetes \\
Male & $46(18.40 \%)$ & $09(3.60 \%)$ & $63(25.20 \%)$ \\
Female & $30(12.00 \%)$ & $20(8.00 \%)$ & $82(32.80 \%)$
\end{tabular}

Conception about blood glucose level

\begin{tabular}{llll} 
Male & $20(8.00 \%)$ & $94(37.60 \%)$ & $04(1.60 \%)$ \\
Female & $24(9.60 \%)$ & $97(38.80 \%)$ & $08(3.20 \%)$ \\
\hline
\end{tabular}


Assessment of blood glucose level of respondents Estimation of blood glucose level showed that about 198 people $(79.20 \%)$ had fasting blood glucose level $>7.0 \mathrm{mmol} / 1$ suffering from diabetes. Thirty three subjects $(13.20 \%)$ were suffering from impaired glucose tolerance with fasting blood glucose level $>6.1$ to $<7.0 \mathrm{mmol} / 1$ (Table-III). The results also demonstrated that female are more prone to diabetes than men as our study results tabulated that about $53.03 \%$ female had blood glucose level $>7.0$ and $57.58 \%$ had within $>6.1$ to $<7.0 \mathrm{mmol} / 1$ range which is greater than of male's $42.42 \%$ and $46.97 \%$ respectively.

\section{Evaluation of risk factors}

In our study $168(67.20 \%)$ of respondents $\left(\chi^{2}=0.368\right.$; $\mathrm{p}=0.544)$ were greater than 45 years of age which supports the correlation between diabetes and increasing age. In our study respondents, especially women $(54.76 \%)$ were likely to have diabetes more than male (45.23\%) respondents over age 45 and also women less than 45 years of age. But male respondents less than 45 years of age suffer from diabetes more than the male respondents aged over 45 years old. This study has also shown a significant relationship $\left(\mathrm{p}=0.016 ; \chi^{2}=5.849\right)$ between family history and diabetes especially in females. From the table 4 below, most of the respondent as well as diabetic patients are inheritably got this complication.
$155(62.00 \%)$ diabetic patients were inheritably got it where $95(38.0 \%)$ had no diabetic family history. By BMI study of the patients, we found $46.40 \%$ patients $\left(\chi^{2}=2.682 ; \mathrm{p}=0.101\right)$ were overweight $\left(>25 \mathrm{~kg} / \mathrm{m}^{2}\right)$ when $8.1 \%$ of respondents were underweight $\left(<18 \mathrm{~kg} / \mathrm{m}^{2}\right)$. Women (59.48\%) were more obese than male $(40.52 \%)$.

It is evident from the study that most of the patients, $195(78.00 \%)$, were in the high risk region of triglycerides $(200-499 \mathrm{mg} / \mathrm{dl})$ and $55(22.00 \%)$ patients were in normal level $(<200 \mathrm{mg} / \mathrm{dl})$ of triglycerides $\left(\chi^{2}\right.$ $=1.015 ; \mathrm{p}=0.314)$. Women $(52.33 \%)$ possessed a large portion in the high risk region rather than men $(47.67 \%)$ subjects. Again, 74 subjects $(29.60 \%)$ were suffering from high blood pressure $\left(\chi^{2}=0.875 ; \mathrm{p}=\right.$ $0.350)$ while $176(70.40 \%)$ subjects were with normal blood pressure. This study revealed that women $(59.15 \%)$ were suffering hypertension more than men (40.85\%) counterparts.

In this study, it was found that the percentage of subjects aware about serious complications associated with diabetes were heart disease (36\%), hypertension $(29 \%)$, renal disease (14\%), cerebrovascular disease $(8 \%)$, eye diseases $(5 \%)$, other complications $(4 \%)$, diabetic foot disease $(2 \%)$, neuropathy and unknown complication is around (1\%). In our study we have found poor correlation between income, educational level, etc. with the knowledge of diabetes and its risk factor.

Table-III

Fasting glucose level of respondents (according to WHO criteria 2006)

\begin{tabular}{|c|c|c|c|c|c|c|c|}
\hline \multirow{2}{*}{$\begin{array}{l}\text { Condition (blood glucose } \\
\text { level in } \mathrm{mmol} / \mathrm{l})\end{array}$} & \multirow{2}{*}{$\begin{array}{c}\text { Total }(\%) \\
\%\end{array}$} & \multicolumn{3}{|c|}{ Male } & \multicolumn{3}{|c|}{ Female } \\
\hline & & $95 \% \mathrm{CI}$ & $\mathrm{SD}$ & $\%$ & $95 \% \mathrm{CI}$ & $\mathrm{SD}$ & $\%$ \\
\hline Normal $(<6.1)$ & $19(7.60)$ & 50.00 & $0.48-2.19$ & 0.82 & 50 & $0.25-2.42$ & 1.03 \\
\hline $\begin{array}{l}\text { Impaired Glucose } \\
\text { Tolerance }(>6.1 \&<7.0)\end{array}$ & $33(13.20)$ & 42.42 & $1.25-3.42$ & 1.03 & 57.58 & $1.01-4.99$ & 1.89 \\
\hline Diabetes Mellitus (>7.0) & $198(79.20)$ & 46.97 & $9.84-21.16$ & 5.39 & 53.03 & $6.01-29.33$ & 1.11 \\
\hline
\end{tabular}

$\mathrm{CI}=$ Class Interval; $\mathrm{SD}=$ Standard Deviation

Table-IV

Percent distribution with and association by sex and risk factor

\begin{tabular}{|c|c|c|c|c|c|}
\hline Parameter & Category & $\begin{array}{c}\text { Male } \\
(\%)\end{array}$ & $\begin{array}{c}\text { Female } \\
(\%)\end{array}$ & $\begin{array}{l}\text { Total Number } \\
\text { of patients (\%) }\end{array}$ & $\begin{array}{c}\text { Chi Square (d.f) } \\
\text { P value }\end{array}$ \\
\hline \multirow{2}{*}{ Age } & $>45$ & 45.23 & 54.76 & $168(67.20 \%)$ & $0.368(1)$ \\
\hline & $<45$ & 49.37 & 50.63 & $82(32.80 \%)$ & 0.544 \\
\hline \multirow[t]{2}{*}{ Family History } & Yes & 40.65 & 59.35 & $155(62.00 \%)$ & $5.849(1)$ \\
\hline & No & 56.52 & 43.48 & $95(38.00 \%)$ & $0.016^{*}$ \\
\hline \multirow[t]{2}{*}{ Obesity } & Yes & 40.52 & 59.48 & $116(46.4 .0 \%)$ & $2.682(1)$ \\
\hline & No & 51.35 & 48.65 & $134(53.60 \%)$ & 0.101 \\
\hline \multirow[t]{2}{*}{ Excess Triglyceride } & Yes & 47.67 & 52.33 & 195 (78.00\%) & $0.875(1)$ \\
\hline & No & 38.89 & 57.41 & $55(22.00 \%)$ & 0.350 \\
\hline \multirow[t]{2}{*}{ Hypertension } & Yes & 40.85 & 59.15 & 74 (29.60\%) & 1.307 (1)0.253 \\
\hline & No & 48.86 & 51.14 & $176(70.40 \%)$ & \\
\hline
\end{tabular}

* $\mathrm{P}<0.05$ considered significant 


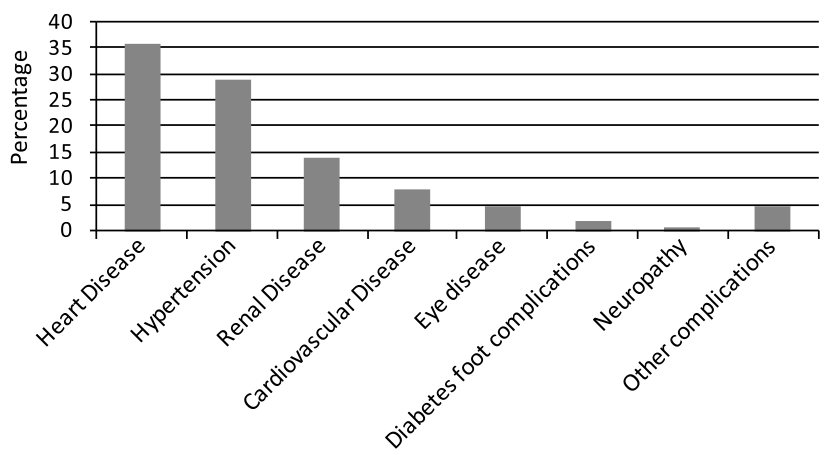

Fig.-1: Percentage of the most serious complication associated with diabetes mellitus

\section{Discussion}

Diabetes mellitus is a chronic disease and is one of the five leading causes of death worldwide that requires ongoing monitoring and treatment. [28] Individuals those who have diabetes always are at higher risk of developing heart disease, stroke, high blood pressure, blindness, kidney disease, nervous system disease, amputations, dental disease, and complications of pregnancy. ${ }^{29}$ Therefore knowledge as well as awareness about diabetes mellitus, its risk factors, complications and management are important aspects for better control this disease and better quality of life. ${ }^{6,30}$

People may be affected to diabetes at any age of life cycle. But probabilities of becoming diabetic increases with the increase of age since people become obese. Some findings previously reported that in developing countries, the majority of people with diabetes are greater than 45 years of age. ${ }^{7}$ We have also found a similar relationship of increasing age with diabetes. It is evident that higher education level was significantly associated with greater knowledge of diabetic symptoms, risk factors and complications. ${ }^{31}$ A study conducted in Singapore demonstrated that diabetes related education had changed the self-care practice among diabetic patients. ${ }^{32}$ Another study showed that education had a significant role in diabetic awareness to keep correct blood glucose level. ${ }^{33}$

It is known that inactivity or a low quantity of physical activity can be a work associated risk factor for diabetes as considering that some professions or occupations, due to its own nature, reduce professionals' physical activity. ${ }^{34}$ In our study it is found that about $34.40 \%$ respondents were housewives which clear the fact that women are more prone to diabetes than men due to sedentary working condition.
Again it has been shown that rural people are less knowledgeable than the people residing in the urban area due to lack of formal education about diabetes. ${ }^{33}$ Previous investigations also validated this fact and showed that rural people had less awareness of blood glucose level and also diabetes in comparison to urban people. ${ }^{35,36}$ As in our study a majority of the population had either misconception or poor conception about diabetes and related causes, symptoms, management and also about control of blood glucose level that justifies that rural people are still in the light of education about diabetes and diabetes related management.

It is generally assumed that male subjects have more knowledge about healthy life style in parallel to female. Several studies performed earlier also showed that males have better understanding of diabetes symptoms, signs and complications ${ }^{31,37}$ as well as about diabetes mellitus, healthy diet and life style modification $^{24}$ in analogy to females. In our study, we had also found similar type of results where majority of the study subjects were female.

Diabetes is a group of metabolic diseases which is also an inherited complication. ${ }^{27}$ The association between family history of diabetes and risk for the disease has been well documented. ${ }^{38-40}$ Individuals having a family history of diabetes can be at the risk of type 2 diabetes more than two to six times when compared to individuals with no family history of the disease. ${ }^{39}$ There is a complex relationship of family history and diabetes as family medical history provides valuable genomic information about the combination of inherited genetic susceptibilities and shared environmental and behavioral factors. ${ }^{41}$ Thus the family history can be used as part of a comprehensive risk assessment for an individual and also in the prevention, early detection, and treatment of diabetes.

Obesity and low physical activity are predisposing factors for diabetes mellitus morbidity. ${ }^{42}$ Studies proved that obese person has greater chance to be diabetic than non-obese person. There is an agedependent relationship between obesity and diabetes mellitus which is well established by investigations carried out previously specially throughout the entire Asia-Pacific region. ${ }^{12}$ Moreover it was found that the effects of obesity on incident diabetes mellitus were significantly greater in women than men. ${ }^{43}$ Our study also found similar results while finding relationship between obesity and diabetes that matches the previous study reports. 
High blood cholesterol and triglycerides level can be a predictor of diabetes since elevated cholesterol levels are often seen in people with insulin resistance. ${ }^{44}$ Moreover, diabetes patient should aim to keep his or her blood pressure well controlled. Uncontrolled blood glucose leads to high blood pressure which is one of several risk factors that can increase his or her chance of developing heart disease, a stroke and some other complications. ${ }^{45}$ Our present study pointed out that hyperlipidemia, hypertriglyceridemia and hypertension are coexisting with diabetes mellitus which maybe in tailoring management of diabetes among the patients.

\section{Conclusion}

Diabetes Mellitus (DM) is now recognized as a global health challenge of the 21 st century. Current projections estimate that prevalence of DM worldwide may double over the next two decades. Asia is emerging as the epicenter of diabetes epidemic. Like all other developed and developing countries prevalence and incidence of diabetes is also increasing in Bangladesh. According to the IDF Diabetes Atlas, the diabetes patients in Bangladesh will have risen to $7.9 \%$ by the year 2030, which is why it is necessary to act now. In our study we found that family history of diabetes, age, obesity, etc. play significant role in the advent of diabetes. Physical inactivity and uncontrolled blood glucose lead to diabetes. Most of the people are unaware of their blood glucose level and many of them do not know that they are suffering from impaired glucose tolerance. People are also ignored of diabetes related complications. This study is representative of the other regions of Bangladesh. Government must take initiative to make people educated about diabetes, related risk factor, complications derived from diabetes, management system. Diabetic health education programs should be developed on a community level to raise awareness. Physicians medicating diabetic patients should also give equal importance to complications and patient education about risk factors for successful management of diabetes. Active association of the community members in this process will result in better diabetic awareness and health empowerment.

\section{References}

1. American Diabetes Association (ADA): Diagnosis and classification of diabetes mellitus. Diabetes Care 2008;31:55-60.

2. Fowler M. Microvascular and macrovascular complications of diabetes. Clin Diabetes 2008;26: 77-82.
3. Halpern A, Mancini M, Magalhaes M, et al. Metabolic syndrome, dyslipidemia, hypertension and type 2 diabetes in youth: from diagnosis to treatment. Diabetol Metab Syndr 2010;2:55.

4. Abegunde D, Mathers C, Adam T, et al. The burden and costs of chronic diseases in low-income and middle-income countries. Lancet 2007;370:19291938.

5. Hjelm K, Mufunda E, Nambozi G, et al. Preparing nurses to face the pandemic of diabetes mellitus: a literature review. J Adv Nurs 2003;41:424-ê 34 .

6. Wild S, Roglic G, Green A, et al. Global prevalence of diabetes: estimates for the year 2000 and projections for 2030. Diabetes Care 2004;27:10471053.

7. King H, Aubert RE, Herman WH. Global burden of diabetes, 1995-2025: Prevalence, numerical estimates, and projections. Diabetes Care 1998; 21:1414-1431.

8. International Diabetes Federation (IDF): Country estimates table 2011. IDF diabetes atlas, 6th ed. 2012. Available at: www.idf.org/sites/default/files/ EN_6E_Atlas_Full_0.pdf. Accessed 13 May 2015.

9. Satman I, Yilmaz T, Sengul A, et al. Populationbased study of diabetes and risk characteristics in Turkey: results of the Turkish Diabetes Epidemiology Study (TURDEP). Diabetes Care 2002; 25: 1551-1556.

10. Grandinetti A, Chang HK, Mau MK, et al. Prevalence of glucose intolerance among Native Hawaiians in two rural communities, Native Hawaiian Health Research (NHHR) Project. Diabetes Care 1998; 21: 549-554.

11. King H, Rewers M. Global estimates for prevalence of diabetes mellitus and impaired glucose tolerance in adults. Diabetes Care 1993;16:157-177.

12. Gulabani M, John M, Isaac R. Knowledge of diabetes, its treatment and complications amongst diabetic patients in a tertiary care hospital. Indian $\mathrm{J}$ Community Med 2008;33:204-206.

13. Bangladesh population and housing census 2011 . Dhaka: Bangladesh Bureau of Statistics, Government of the People's Republic of Bangladesh. 2012.

14. Saquib N, Saquib J, Ahmed T, et al. Cardiovascular diseases and Type 2 Diabetes in Bangladesh: A systematic review and meta-analysis of studies between 1995 and 2010. BMC Public Health 2012;12:434.

15. International Diabetes Federation. Diabetic Association of Bangladesh supports Unite for Diabetes 2006. Available at: www.world diabetesday.org/node/2918. Accessed May 152015. 
16. McKeigue $\mathrm{P}$, Shah B, Marmot M. Relation of central obesity and insulin resistance with high diabetes prevalence and cardiovascular risk in South Asians. Lancet 1991;337: 382-386.

17. McKeigue PM, Pierpoint T, Ferrie JE, Marmot MG. Relationship of glucose intolerance and hyperinsulinemia to body fat pattern in South Asians and Europeans. Diabetologia 1992;35: 785-791.

18. National Institute of Population Research and Training (NIPORT), Mitra and Associates (MA), ORC Macro (ORCM). Bangladesh Demographic and Health Survey, 1999-2000. Dhaka, Bangladesh and Calverton, Maryland USA Maryland, National Institute of Population Research and Training, Mitra and Associates, and ORC Macro, 2001, Additional data from personal communication: Noureddine Abderrahim of ORC MacroBangladesh Bureau of Statistics: Statistical Pocket Book of Bangladesh. 2000. Singha AC, Ed. Statistical Division, Ministry of Planning, Government of the People's Republic of Bangladesh.

19. West KM, Kalbfleisch JM. Glucose tolerance, nutrition and diabetes in Uruguay, Venezuela, Malaya and East Pakistan. Diabetes 1966;15:9-18.

20. Sayeed MA, Hussain MZ, Banu A, et al. Effect of socioeconomic risk factor on difference between rural and urban in the prevalence of diabetes in Bangladesh. Diabetes Care 1997;20:551-555.

21. Imam $\mathrm{T}$, Hossain MB. Diabetes prevalence: a comparison between urban and rural areas of Bangladesh. Int Res J Appl Life Sci 2012;1:114126.

22. Habib SS, Aslam M. Risk factors, knowledge and health status in diabetic patients. Saudi Med J 2003;24:1219-1224.

23. Mehrotra R, Bajaj S, Kumar D, et al. Influence of education and occupation on knowledge about diabetes control. Natl Med J India 2000;13:293-296.

24. Lged.gov.bd. District LGED. 2011. Available at: www.lged.gov.bd/DistrictLGED.aspx? DistrictID $=7$. Accessed 30 Jun. 2015.

25. Weadapt.org. 2012. NCAP Bangladesh: Noakhali | weADAPT 4.0. Available at: http://weadapt.org/ knowledge-base/vulnerability/ncap-bangladeshnoakhali. Accessed 30 Jun. 2015.

26. Ahmad M. Living in the coast, Urbanization. PDOICZMP (Program Development Office for Integrated Coastal Zone Management Plan). Water Resources Planning Organization (WARPO), Ministry of Water Resources, Government of the People's Republic of Bangladesh. 2005.

27. Grandy S, Chapman RH, Fox KM. Quality of life and depression of people living with type 2 diabetes mellitus and those at low and high risk for type 2 diabetes: findings from the Study to Help Improve Early evaluation and management of risk factors leading to Diabetes (SHIELD). Int $\mathrm{J}$ Clin Pract 2008;62:562-568.

28. Akinci F, Healey BJ, Coyne JS. Improving the health status of US working adults with type 2 diabetes mellitus. Dis Manage Health Outcomes 2003;11: 489-498.

29. Ángeles-Llerenas A, Carbajal-Sánchez N, Allen B, Zamora-Muñoz S, Lazcano-Ponce E. Gender, body mass index and sociodemographic variables associated with knowledge about type 2 diabetes mellitus among 13293 Mexican students. Acta Diabetol 2005;42:36-45.

30. Nisar N, Khan IA, Qadri MH, et al. Knowledge and Risk assessment of diabetes mellitus at primary care level: A Preventive approach required combating the disease in a developing country. Pak J Med Sci 2008;24:667-672.

31. Wee HL, Lisc HO. Public awareness of diabetes mellitus in Singapore. Singapore Med J 2002; 43:128-134.

32. Hoque MA, Islam MS, Khan MAM, et al. Knowledge of diabetic complications in a diabetic population. $\mathrm{J}$ Medicine 2009;10:90-93.

33. Almeida VCF, Zanetti ML, Almeida PC, et al. Occupation and risk factors for type 2 diabetes: a study with health workers. Rev Latino-Am Enfermagem 2011;19:476-484.

34. Sabri AA, Qayyaum MA, Saigol NU, et al. Comparing knowledge of diabetes mellitus among rural and urban diabetics. Megill J Med 2007;10:87-89.

35. Moodley LM. An assessment of the level of knowledge about diabetes mellitus among diabetic patients in a primary healthcare setting. SA Fam Pract 2007:49:54-59.

36. Hawthorne K, Tomlinson S. Pakistani Muslims with type 2 diabetes mellitus: effect of sex, literacy skills, known diabetic complications and place of care on diabetic knowledge, reported self-monitoring management and glycaemic control. Diabet Med 1999; 16: 591-597.

37. Ulvi $\mathrm{O}$, Chaudhary $\mathrm{R}$, Ali $\mathrm{T}$, et al. Investigating the awareness level about Diabetes Mellitus and associated factors in Tarlai (Rural Islamabad). J Pak Med Assoc 2009;59:798-801.

38. Harrison TA, Hindorff LA, Kim H, et al. Family history of diabetes as a potential public health tool. Am J Prev Med 2003;24:152-159. 
BJM Vol. 27 No. 1

39. Meigs JB, Cupples LA, Wilson PW. Parental transmission of type 2 diabetes: the Framingham Offspring Study. Diabetes 2000;49:2201-2207.

40. Yoon PW, Scheuner MT, Khoury MJ. Research priorities for evaluating family history in the prevention of common chronic diseases. Am J Prev Med 2003;24:128-135.

41. Wilborn C, Beckham J, Campbell B, et al. Obesity: prevalence, theories, medical consequences, management, and research directions. J Int Soc Sports Nutr 2005;2:24-31.
Awareness evaluation of diabetics of Bangladesh

42. Sasai H, Sairenchi $T$, Iso $H$, et al. Relationship between obesity and incident diabetes in middleaged and older Japanese adults: The Ibaraki Prefectural Health Study. Mayo Clin Proc 2010;85:36-40.

43. Kahn, B., Flier, J. Obesity and insulin resistance. $\mathrm{J}$ Clin Invest 2000;106:473-481.

44. Sowers J, Epstein M, Frohlich E. Diabetes, hypertension, and cardiovascular disease an update. Hypertension 2001;37:1053-1059. 